\title{
Under Nutrition Status and Its Determinants among Adult HIV and AIDS Clients Enrolled on Antiretroviral Therapy at Nigest Elleni Mohammed Memorial Hospital, Southern Ethiopia
}

\author{
Wondmagegn G Shiferaw ${ }^{1 \#}$, Assefa A Jegora ${ }^{1 \#}$, Lire Lema ${ }^{2 \#}$ and Beminet M Gebremariam² \\ ${ }^{1}$ Department of Nursing, College of Medicine and Health Sciences Wachemo University, Hossana, Ethiopia \\ ${ }^{2}$ Department of Public Health, College of Medicine and Health Sciences, Wachemo University, Hossana, Ethiopia \\ \#Authors contributed equally
}

\begin{abstract}
Background: HIVIAIDS and malnutrition effects are interrelated and exacerbate one another in a vicious cycle. HIV specifically affects nutritional status by increasing energy requirements, reducing food intake and adversely affecting nutrient absorption and metabolism. In spite of the number of People Living with HIV ever enrolled on ART increases significantly in Ethiopia. Nutritional care and other supports which help for the success of treatment received insufficient attention. The aim of this study was to assess the prevalence of undernutrition status and its determinants among adult HIVIAIDS Clients enrolled on ART at Nigest Elleni Mohammed Memorial Hospital in Hosanna Town, Southern Ethiopia.
\end{abstract}

Method: Institution based cross-sectional quantitative study was conducted using systematic random sampling technique with sample size of 234. From each sampled patient, interview and anthropometric data were collected. Bivariate and multivariate logistic regression analysis was used and the variables which had significant association were identified on the basis of $p$-value $\leq 0.05$ and AOR, with $95 \% \mathrm{Cl}$.

Results: Among adult HIVIAIDS Clients in rolled in ART, $32.5 \%$ of them were under nourished $\left(B M \mid<18.5 \mathrm{Kg} / \mathrm{m}^{2}\right)$. ART patients had no nutritional supports ( $A O R=2.22)$, patients who feed less than 3 times in a day $(A O R=3.29)$ and had smoking habit $(A O R=6.06)$ were more likely to be under nourished and those patients in WHO Clinical stage 3 $(A O R=0.12)$ were less likely to be under nourished.

Conclusion: This study revealed that under nutrition among adult HIVIAIDS Clients in rolled in ART was high prevalent problem in the study area. WHO clinical stage, daily food intake, nutritional support, smoking status was identified as the determinants of under nutrition. Current study identified that there is a need to design and implement nutritional interventions including nutritional support in items or financially together with healthy habit counselling as part of integrated ART service for effective patient treatment outcome.

Keywords: HIV/AIDS; ART; Under nutrition; BMI; Southern Ethiopia

Abbreviations: AIDS: Acquired Immune Deficiency Syndrome; AOR: Adjusted Odd Ratio; ART: Anti-Retroviral Therapy; BMI: Body Mass Index;CD4:Cluster of Differentiation 4;CEM: Chronic Energy Malnutrition; COR: Crude Odd Ratio; EDHS: Ethiopian Demographic and Health Survey; FMOH: Federal Ministry of Health; FANTA: Food and Nutrition technical Assistance; FAO: Food and Agriculture Organization; HIV: Human Immunodeficiency Virus; KG: Kilogram; HT: Height; NEMMH: Nigest Eleni Mohammed Memorial hospital; OI: Opportunistic Infection; PLWHA: People Living With HIV/AIDS; RUTF: Ready to Use Therapeutic Food; SNNPR: South Nation Nationality Peoples Region; WHO: World Health Organization

\section{Introduction}

The Human Immunodeficiency Virus pandemic remains to have a prominent global impact, particularly among the world's resourcelimited settings. According to Global AIDS Progress Report of 2014, approximately 36.9 million people were living with HIV and AIDS. In sub-Saharan Africa, there were 24.7 million people living with HIV and 1.1 million people died of AIDS-related causes in 2013 [1,2]. The prevalence of HIV was 1.5 percent among adults age 15-49 in Ethiopia based on Demographic and Health Survey of 2011 [3]

HIV specifically affects nutritional status by increasing energy requirements, reducing food intake, and adversely affecting nutrient absorption and metabolism. Asymptomatic and symptomatic adults have energy requirements increases by $10 \%$ and $30 \%$ respectively to maintain body weight and physical activity $[4,5]$.

The latest available estimates indicate that about 795 million people in the world were undernourished. In Sub Saharan Africa including Ethiopia about 23.2\%individuals were undernourished [6]. In Ethiopia the number of People Living with HIV (PLHIV) ever enrolled on ART increases significantly, currently, 871,334 PLHIV enrolled on ART [7].

Malnutrition and HIV/AIDS compound one another. People Living with HIV and AIDS (PLWHA) are more likely to become malnourished due to reduced food intake resulting from appetite loss and difficulty eating, possibly as a result of infections, side effects of

*Corresponding author: Beminet M Gebremariam, Department of Public Health, College of Medicine and Health Sciences, Wachemo University, Hossana, Ethiopia; Tel: +251912122934; E-mail: bemnismart@gmail.com

Received September 01, 2017; Accepted September 22, 2017; Published September 29, 2017

Citation: Shiferaw WG, Jegora AA, Lema L, Gebremariam BM (2017) Unde Nutrition Status and Its Determinants among Adult HIV and AIDS Clients Enrolled on Antiretroviral Therapy at Nigest Elleni Mohammed Memorial Hospital, Southern Ethiopia. J AIDS Clin Res 8: 733. doi: 10.4172/2155-6113.1000733

Copyright: (C) 2017 Shiferaw WG, et al. This is an open-access article distributed under the terms of the Creative Commons Attribution License, which permits unrestricted use, distribution, and reproduction in any medium, provided the original author and source are credited. 
Citation: Shiferaw WG, Jegora AA, Lema L, Gebremariam BM (2017) Under Nutrition Status and Its Determinants among Adult HIV and AIDS Clients Enrolled on Antiretroviral Therapy at Nigest Elleni Mohammed Memorial Hospital, Southern Ethiopia. J AIDS Clin Res 8: 733 . doi: $10.4172 / 2155-6113.1000733$

Page 2 of 6

medication, or depression. Poor absorption of nutrients that may be the result recurrent/chronic diarrhea and HIV-caused intestinal cell damage. And then the will develop malnutrition again it contributes to immune impairment, making the body vulnerable to frequent illnesses [8-10].

Antiretroviral therapy is critical to suppression of viral replication, reduced destruction of $\mathrm{CD} 4$ cells, prevention of viral resistance, promotion of immune reconstitution, and slowed disease progressions [11-13]. Nutrient intake can improve antiretroviral absorption and tolerance. Poor nutritional status in PLHIV speeds the disease progression increases morbidity, and reduces survival time. Good nutrition for PLHIV has been proven to increase resistance to infection, help PLHIV maintain weight, improve drug compliance and drug efficacy [14-16].

Despite there are a growing number of ART users in Ethiopia, nutritional care and support get insufficient attention to the success of treatment and also there is little evidence against to the nutritional condition of peoples' living HIV and AIDS those who are enrolled in ART care in the study area. The results of this study will also serve as baseline data onto program managers and decision makers to design nutritional intervention. Therefore this study aimed to assess the undernutrition status and its determinants among adult HIV/AIDS Clients enrolled on ART at Nigest Elleni Mohammed Memorial Hospital in Hosanna Town, Southern Ethiopia.

\section{Materials and Methods}

\section{Study area and period}

The study was carried out in Nigest Elleni Mohammed Memorial Hospital in Hosanna town the capital city of Hadiya Zone SNNPR State situated $196 \mathrm{Km}$ from Hawassa and $232 \mathrm{Km}$ from Addis Ababa. The Hospital was built in 1984 GC and it is serving 3.5 million people from different zones with 110 beds. A total of 882 adult HIV/AIDS patients have been enrolled at Nigest Elleni Mohammed Memorial Hospital ART care. We have completed the study from November 01 to June 14, 2016.

\section{Study design and population}

Institutional based cross-sectional quantitative study was conducted to assess adult undernutrition status and its determinants of ART users at Nigest Elleni Mohammed Memorial Hospital. The source populations were all adult HIV and AIDS patients that are enrolled in ART care clinic in Nigest Elleni Mohammed Memorial Hospital. The study population was the sampled adult HIV/AIDS patients who are actively taking ARV drugs at Nigest-Elleni Mohammed Memorial Hospital. Patients who were actively following ART care clinic in Nigest Elleni Mohammed Memorial Hospital and aged 18years and older, not have physical deformity and nonpregnant women were included in the study. Patients who seriously ill at the time of data collection were excluded.

\section{Sampling size determination}

The sample size was determined using single population proportion formula taking $25.5 \%$ [17] the prevalence of malnourished people living HIV and AIDS at Felege-Hiwot Referral Hospital in Bahirdar with 5\% marginal error and $95 \%$ confidence interval (CI) of certainty (alpha $=0.05)$. Since the source populations $(882)$ which were $<10000$, an adjustment formula was used. By taking $5 \%$ non-response rate, the total sample size was 234 . Systematic random sampling was used and we have taken every three $\left(\mathrm{k}^{\text {th }}\right.$ interval $\left.=3\right)$ of the daily attended clients consecutively and to start the first case a lottery method was used.

\section{Data collection procedure}

Data was collected using structured questionnaire and anthropometric measurements. Three collection team members participated. The weight of participants was taken using standard beam balance and the scale will be checked at zero before and after each measurement. Participants' weight was measured after removing heavy clothes and recorded to the nearest $0.1 \mathrm{~kg}$. Height measurement of participants was taken using the standard measuring scale and height was recorded to the nearest $0.1 \mathrm{~cm}$. To determine undernutrition status, BMI was calculated. The standard cut-offs that we used: $<18.5 \mathrm{~kg} / \mathrm{m}^{2}$ was under nourished (Chronic Energy deficiency or CED), 18.5-24.9 $\mathrm{kg} / \mathrm{m}^{2}$ was normal.

\section{Data quality management, processing and analysis}

Questionnaire prepared in English was translated into the Amharic language to make data collection easier and back to English for checking language consistency. Pre-testing of the questionnaire was done on 15 ART care clients in the Hossana Health Center a week prior to the actual survey. The collected data was checked out for the completeness and clarity by the students. This quality checking is done daily after data collection and amendments were made before the next data collection measure. The data was collected by 3 B.Sc. Nurses for 15 days. After data collection, each questionnaire was checked for competence and code was given before data entry. Data entry and analysis was done by SPSS version 16.0. To identify the determinants of undernutrition status among Adult HIV and AIDS clients enrolled on ART in this study logistic regression analysis was done. A variable with $\mathrm{P}$-value $<0.25$ was transferred to multivariate analysis which helps all associated variables in bivariate analysis to compete with dependent variable together in order to control confounding factors. Lastly, variables with a p-value $<0.05$ and AOR, with $95 \%$ CI were identified to measure the strength of the associations.

\section{Ethical consideration}

Ethical clearance was obtained from an ethical review committee of Wachemo University, College of Medicine and health science. Official permission letter was sent to Nigest Elleni Mohammed Memorial Hospital in which the actual data collection was performed. The purposes and importance of the study were explained and informed consent was secured from each participant. Confidentiality was maintained at all levels of the study.

\section{Results}

\section{Socio-demography characteristics of the respondents}

A total of 234 adult patients enrolled on ART were involved in the study with response rates of $100 \%$. From them, 135 (57.7\%) of the participants was females and 126 (53.8\%) were between age group $30-45$ years. The majority 147 (63.6) was protestants and $167(71.4 \%)$ from Hadiya ethnic group. Most were urban dwellers 148 (63.2\%), $144(61.5 \%)$ respondents had an occupation and more than half of the respondents $137(57.7 \%)$ had monthly income below 1000 ETB (Table 1).

\section{Clinical profiles and ART status of the study participants}

The HIV status of patients showed that 95 (40.6) were at WHO clinical stage II. Diarrhea of $58(24.8 \%)$ respondents was the most common GI manifestation. 83 patients (35.5\%) were with a CD4 count of 351-500 cells/ $\mu$ l. 91 (38.9) patients had a current or past history of opportunistic infections, 109 patients (46.6\%) were on ART treatment 
Citation: Shiferaw WG, Jegora AA, Lema L, Gebremariam BM (2017) Under Nutrition Status and Its Determinants among Adult HIV and AIDS Clients Enrolled on Antiretroviral Therapy at Nigest Elleni Mohammed Memorial Hospital, Southern Ethiopia. J AIDS Clin Res 8: 733 . doi: $10.4172 / 2155-6113.1000733$

Page 3 of 6

\begin{tabular}{|c|c|c|}
\hline Variables & Number & Percent \\
\hline \multicolumn{3}{|l|}{ Sex of respondents } \\
\hline Male & 99 & 42.3 \\
\hline Female & 135 & 57.7 \\
\hline \multicolumn{3}{|l|}{ Age respondent } \\
\hline $18-29$ & 50 & 21.4 \\
\hline $30-45$ & 126 & 53.8 \\
\hline$\geq 45$ & 58 & 24.8 \\
\hline \multicolumn{3}{|l|}{ Marital status } \\
\hline Married & 111 & 47.4 \\
\hline Divorced & 19 & 8.1 \\
\hline Widowed & 61 & 26.1 \\
\hline Unmarried & 43 & 18.4 \\
\hline \multicolumn{3}{|l|}{ Family size } \\
\hline$<3$ & 79 & 33.8 \\
\hline $3-6$ & 112 & 47.9 \\
\hline$\geq 7$ & 43 & 18.4 \\
\hline \multicolumn{3}{|l|}{ Residency } \\
\hline Urban & 148 & 63.2 \\
\hline Rural & 86 & 36.8 \\
\hline \multicolumn{3}{|l|}{ Ethnicity } \\
\hline Hadiya & 167 & 71.4 \\
\hline Kembata & 29 & 12.4 \\
\hline Silte & 16 & 6.8 \\
\hline Gurage & 12 & 5.1 \\
\hline Others & 10 & 4.3 \\
\hline \multicolumn{3}{|l|}{ Religion } \\
\hline Protestant & 147 & 63.6 \\
\hline Muslim & 22 & 9.5 \\
\hline Orthodox & 43 & 18.6 \\
\hline Catholic & 13 & 5.6 \\
\hline Others & 6 & 2.6 \\
\hline \multicolumn{3}{|l|}{ Occupation } \\
\hline No occupation & 90 & 38.5 \\
\hline Had occupation & 144 & 61.5 \\
\hline \multicolumn{3}{|l|}{ Educational status } \\
\hline Illiterate & 29 & 12.6 \\
\hline Primary & 20 & 8.7 \\
\hline Secondary & 58 & 25.1 \\
\hline $\begin{array}{l}\text { Higher secondary and } \\
\text { above }\end{array}$ & 46 & 19.9 \\
\hline \multicolumn{3}{|l|}{ Monthly income } \\
\hline$<1,000$ ETB* & 135 & 57.7 \\
\hline$\geq 1,000$ ETB & 99 & 42.3 \\
\hline
\end{tabular}

*ETB: Ethiopian Birr

Table 1: Socio-demographic characteristics of respondents at Nigest Elleni Mohammed Memorial Hospital, Hosanna, Ethiopia, $2016(n=234)$

regimen 1e (TDF+3TC+NVP), most of the patients have taken ART for more than three years (Table 2).

\section{Food and lifestyle-related characteristics}

The study showed that $170(72.6 \%)$ adult patients were changed their feeding style after knowing their HIV status. About 60 (25.6\%) patients were consumed High fat containing foods. Tap water was the most common type of water used by $191(81.6 \%)$ respondents. From the total study participants, $124(53.0 \%)$ of them has received feeding counseling (Table 3).

\begin{tabular}{|c|c|c|}
\hline Variables & Number & Percent \\
\hline \multicolumn{3}{|l|}{ Eating fat } \\
\hline No & 153 & 65.4 \\
\hline Yes & 81 & 34.6 \\
\hline \multicolumn{3}{|c|}{ Gastrointestinal symptoms } \\
\hline No & 136 & 58.1 \\
\hline Yes & 98 & 41.9 \\
\hline Diarrhea & 58 & 24.8 \\
\hline Indigestion & 21 & 9 \\
\hline Constipation & 19 & 8.1 \\
\hline \multicolumn{3}{|c|}{ WHO clinical stage } \\
\hline Stage 1 & 80 & 34.2 \\
\hline Stage 2 & 95 & 40.6 \\
\hline Stage 3 & 47 & 20.1 \\
\hline Stage 4 & 12 & 5.1 \\
\hline \multicolumn{3}{|l|}{ CD4+ T cell count } \\
\hline$<200$ cells $/ \mu \mathrm{l}$ & 33 & 14.1 \\
\hline 200-350 cells/ $\mu \mathrm{l}$ & 49 & 20.9 \\
\hline $351-500$ cell & 83 & 35.5 \\
\hline$\geq 500$ & 69 & 29.5 \\
\hline \multicolumn{3}{|c|}{ Current/past OI in the past 6 months } \\
\hline No & 143 & 61.1 \\
\hline Yes & 91 & 38.9 \\
\hline \multicolumn{3}{|l|}{ ART regimen } \\
\hline $1 e$ & 109 & 46.6 \\
\hline $1 c$ & 51 & 21.8 \\
\hline $1 d$ & 35 & 15 \\
\hline $1 \mathrm{a}$ & 9 & 3.8 \\
\hline $1 f$ & 8 & 3.4 \\
\hline \multicolumn{3}{|l|}{$2 b$} \\
\hline \multicolumn{3}{|l|}{ Duration of ART } \\
\hline$<6$ months & 45 & 19.2 \\
\hline 6 months- 3 years & 80 & 34.2 \\
\hline$\geq 3$ years & 109 & 46.6 \\
\hline
\end{tabular}

Table 2: Clinical profiles and ART status of the study participants at Nigest Elleni Mohammed Memorial Hospital, Hosanna, Ethiopia, 2016

\section{Support and dietary characteristics}

From patients who had no nutritional support, 54 (71\%) became undernourished. In the study patients that fed their meals less than 3 times per day and became undernourished were 20 (26\%) however, 137 (87\%) of patients that enrolled on ART were Fed 3 and more times per day and their nutritional status became normal (Figure 1).

\section{Undernutrition status of adult HIV/AIDS clients}

In the analysis, the prevalence of undernutrition (Chronic Energy deficiency) among adult HIV/AIDS Clients in rolled in ART was $32.5 \%$. From the ART users, 158 (67.5\%) was Normal (BMI $18.5-24.9 \mathrm{Kg} / \mathrm{m}^{2}$ ). The prevalence of undernutrition and normal nutritional status among females were 46 (19.7\%) and 89 (38\%), respectively (Figure 2).

Determinants of undernutrition status among adult HIV/ AIDS patients enrolled in ART

In the study educational status, occupational status, monthly income CD4 count, WHO clinical stage, duration on ART, eating fat-containing foods, daily food intake, daily water consumption, nutritional support, smoking status were significantly associated with undernutrition status in bivariate analysis. The study result of multivariate analysis indicated 
Citation: Shiferaw WG, Jegora AA, Lema L, Gebremariam BM (2017) Under Nutrition Status and Its Determinants among Adult HIV and AIDS Clients Enrolled on Antiretroviral Therapy at Nigest Elleni Mohammed Memorial Hospital, Southern Ethiopia. J AIDS Clin Res 8: 733 . doi: $10.4172 / 2155-6113.1000733$

Page 4 of 6

\begin{tabular}{|c|c|c|}
\hline Variables & Number & Percent \\
\hline \multicolumn{3}{|c|}{ Change of feeding style after knowing HIV status } \\
\hline No & 170 & 72.6 \\
\hline Yes & 64 & 27.4 \\
\hline \multicolumn{3}{|c|}{ Eat High fat containing foods } \\
\hline No & 174 & 74.4 \\
\hline Yes & 60 & 25.6 \\
\hline \multicolumn{3}{|c|}{ Frequency of daily food intake } \\
\hline$<3$ & 41 & 17.5 \\
\hline$\geq 3$ & 193 & 82.5 \\
\hline \multicolumn{3}{|c|}{ Daily water intake (L) } \\
\hline$<1$ & 14 & 6 \\
\hline $1-2$ & 7 & 3 \\
\hline$\geq 3$ & 191 & 81.6 \\
\hline \multicolumn{3}{|l|}{ Type of water } \\
\hline No selection & 7 & 3 \\
\hline Tap & 191 & 81.6 \\
\hline Boiled & 1 & 0.4 \\
\hline Treated & 4 & 1.7 \\
\hline Others & 31 & 13.2 \\
\hline \multicolumn{3}{|c|}{ Food counseling } \\
\hline No & 110 & 47 \\
\hline Yes & 124 & 53 \\
\hline \multicolumn{3}{|c|}{ Nutritional support } \\
\hline Had no support & 188 & 80.3 \\
\hline RUTF & 46 & 19.7 \\
\hline \multicolumn{3}{|c|}{ Regular physical exercise } \\
\hline No & 199 & 85 \\
\hline Yes & 45 & 15 \\
\hline \multicolumn{3}{|l|}{ Alcohol use } \\
\hline No & 193 & 82.5 \\
\hline Yes & 41 & 17.5 \\
\hline \multicolumn{3}{|l|}{ Smoking } \\
\hline No & 218 & 93.2 \\
\hline Yes & 16 & 6.8 \\
\hline
\end{tabular}

Table 3: Food and life style related characteristics of the study participants at Nigest Elleni Mohammed Memorial Hospital, Hosanna, Ethiopia, $2016(n=234)$.

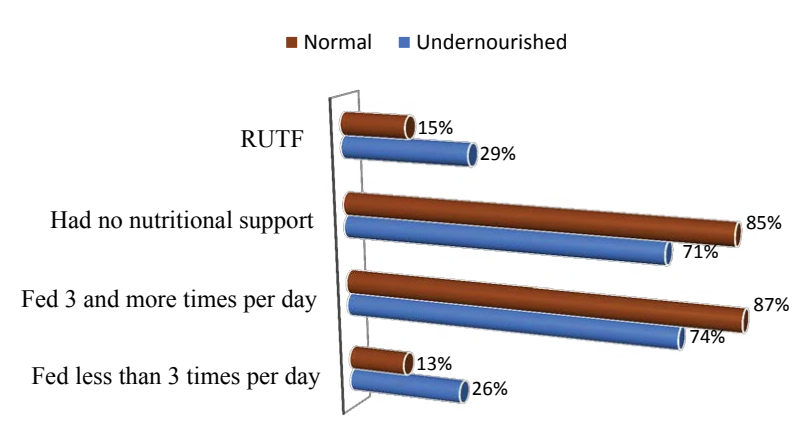

Figure1: Daily feeding frequency, nutritional support and undernutrition status among adult HIV and AIDS patients enrolled in ART at Nigest Ellen Mohammed Memorial Hospital, Hosanna, Ethiopia, 2016

that WHO clinical stages, daily food intake, nutritional support, smoking status were identified as the determinants of under nutrition in the study area. In the study daily food intake of ART patient was found one of the determinants of undernutrition, patients who feed less than 3 times in a day were 3.29 times more likely to be undernourished than patients who eat 3 or more times. $(\mathrm{AOR}=3.29 ; 95 \%$; $\mathrm{CI}(1.49,7.28)$.

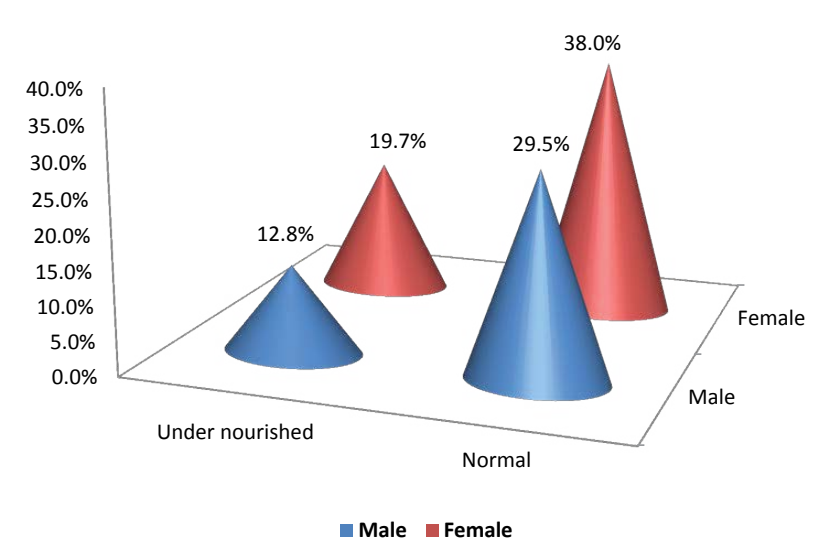

Figure 2: Under nutrition status and sex distribution of adult HIVIAIDS Clients in enrolled in ART at Nigest Elleni Mohammed Memorial Hospital, Hosanna, Ethiopia, 2016.

Illness of patient within WHO Clinical Stage was one of the significant risk factors undernutrition in the study area. Those patients with the illness at WHO Clinical stage 3 were $88 \%$ less likely to be undernourished than WHO Clinical stage 1 ART patients (AOR $=0.12$ 95\% CI: 0.03, 0.55). Having nutritional supports became one of the risk factors which significantly associated with undernutrition, those ART patients who had no nutritional support were 2.21 more likely to become Undernourished (chronic energy deficient) than who had no support $(\mathrm{AOR}=2.28$ 95: $\mathrm{CI}$ : $(1.27,3.85)$. Comparing from ART patients who did had smoking habit those patients who had smoking habits were 6.06 times more likely to be undernourished $(\mathrm{AOR}=6.06 ; 95 \% \mathrm{CI}$ : $1.12,32.8$ ) (Table 4).

\section{Discussion}

The prevalence of undernutrition among adult HIV/AIDS Clients in rolled in ART was 32.5\%. From ART users 158 (67.5\%) were Normal (BMI 18.5-24.9 Kg/m²). The undernutrition in this study was higher than the study conducted in Kathmandu Valley Health center, Nepal 19.9\%, Butajira Hospital, 25.2\%, FelegeHiwot, Amhara Region of Ethiopia 25.5\% and East Wollega Zone (26.47\%) [16-19]. On the other hand, the prevalence of undernourished ART clients in the study was lower than studies conducted in Tigray, northern parts of Ethiopia $50.5 \%$ [20]. The difference of under nutrition may reflect due to population difference, sample characteristics, the existence of different socio-economic and other factors of the study.

Illness of patient within WHO Clinical Stage was one of the significant risk factors undernutrition in the study area. Those patients in WHO Clinical stage 3 were $88 \%$ times less likely to be under nourished than WHO Clinical stage 1 ART patients, this result were in contrary with the finding in Nepal [16] and also study HIV referral center in Singapore which indicated that Patients are often not diagnosed or do not commence ART until they have advanced disease [11]. The possible explanation for this finding could be patients with WHO clinical stage 3 starts ART treatment without CD4 count and get a chance to start drug early that make drug adaptation easier than stage one. Also, stage one patient mostly is asymptomatic so they might not start drug before their CD4 count decreases and immunity lowers.

Having nutritional supports became one of the risk factors which significantly associated with undernutrition, those ART patients who had no any nutritional support were 2.22 times more likely to become 
Citation: Shiferaw WG, Jegora AA, Lema L, Gebremariam BM (2017) Under Nutrition Status and Its Determinants among Adult HIV and AIDS Clients Enrolled on Antiretroviral Therapy at Nigest Elleni Mohammed Memorial Hospital, Southern Ethiopia. J AIDS Clin Res 8: 733 . doi: $10.4172 / 2155-6113.1000733$

Page 5 of 6

\begin{tabular}{|c|c|c|c|c|c|}
\hline \multirow[t]{2}{*}{ Explanatory Variables } & \multicolumn{2}{|c|}{ Undernutrition Status } & \multirow[t]{2}{*}{ COR $95 \% \mathrm{Cl}$} & \multirow[t]{2}{*}{ AOR $95 \% \mathrm{Cl}$} & \multirow[t]{2}{*}{ P-Value } \\
\hline & Under nourished & Normal & & & \\
\hline \multicolumn{6}{|l|}{ WHO clinical stage } \\
\hline Stage 1 & 31 & 49 & 1 & 1 & \\
\hline Stage 2 & 22 & 73 & $0.476(0.247,0.91)$ & $0.283(0.063,1.26)$ & 0.099 \\
\hline Stage 3 & 16 & 31 & $0.816(0.384,1.73)$ & $0.123(0.028,0.54)$ & $0.006^{*}$ \\
\hline Stage 4 & 7 & 5 & $2.213(0.645,7.59)$ & $0.221(0.047,1.03)$ & 0.055 \\
\hline \multicolumn{6}{|l|}{ Daily feeding frequency } \\
\hline Less 3 times & 20 & 21 & $2.330(1.172,4630$ & $3.29(1.49,7.28)$ & $0.003^{*}$ \\
\hline 3 and more times & 56 & 137 & 1 & 1 & \\
\hline \multicolumn{6}{|l|}{ Nutritional support } \\
\hline Had no support & 54 & 134 & $2.28(1.18,4.39)$ & $2.22(1.27,3.85)$ & $0.005^{*}$ \\
\hline RUTF & 22 & 24 & 1 & 1 & \\
\hline \multicolumn{6}{|l|}{ Smoking Habit } \\
\hline Yes & 2 & 14 & $0.28(0.06,1.25)$ & $6.06(1.12,32.8)$ & $0.036^{*}$ \\
\hline No & 74 & 144 & 1 & 1 & \\
\hline
\end{tabular}

*Statistically significant at $p$-value $<0.05 ; 1$ is Odds ratio for reference category

Table 4: Factors associated with under nutrition status among adult HIV and AIDS patients enrolled in ART at Nigest Elleni Mohammed Memorial Hospital, Hosanna, Ethiopia, 2016.

Undernourished (chronic energy deficient) than who had nutritional support. The finding was supported by the studies in Central Haiti [21] and Uganda [22]. However, a study in Butajira hospital contradicts with a report which indicates there individuals who were not taking RUTF were $82 \%$ times less likely to be malnourished than those who were taking RUTF [19]. This might be due to patients who were not receiving nutritional support (RUTF) will lose the positive effects of therapeutic foods which help to enhance ART adherence. Moreover, RUTF support may improve the weight of patients.

Comparing from ART patients who did had smoking habit those patients who had smoking habits were 6.06 times more likely to be undernourished. The possible explanation for this finding could be, smoking can lead to body weight loss by increasing the metabolic rate, decreasing metabolic efficiency, decreasing caloric absorption (reduction in appetite) all of which are associated with tobacco use and results decreased immunity so they are susceptible to OIs and leads to economic problem to buy food instead they buy cigarette.

In the study daily food intake of ART patient was fund one of the determinants of undernutrition, patients who fed less than 3 times per day were 3.29 times more likely to be undernourished than patients who fed 3 or more times. The finding was in line with study in Northern Ethiopia in which, inability to get enough and/or quality food was about 2.1 times higher in the non-adherent group [20]. The possible justification for this may be patients who feed frequently gets the adequate energy that might make them productive and increases their immunity against opportunistic infection from food variety and amount they get.

\section{Conclusion}

In the study, the prevalence of undernutrition was high among adult HIV/AIDS Clients in rolled on ART in the study area. Nutritional support, daily food frequency, WHO clinical stage and smoking status were found to be the significant determinants of under nutrition at Nigest Elleni Mohammed Memorial Hospital in Hosanna Town, Southern Ethiopia. The Current study recommended that, there is a need to design and implement nutritional interventions including nutritional support in items or financially together with healthy habit counselling as part of integrated ART service to prevent undernutrition and for effective treatment outcome. Then, further studies needed to identify other key determine of under nutrition status among adult patients enrolled in ART using longitudinal methods.

\section{Authors' Contributions}

WG, AA wrote the proposal of this research. BM, LL revised the proposal and Incorporate some comments. BM wrote the final manuscript. All authors read and approved the final manuscript.

\section{Acknowledgement}

This study received funds from Wachemo University research and community service and the authors want to extend his heartfelt gratitude to Nigest Ellen Mohammed Memorial Hospital and all participants of the research for their cooperation.

\section{References}

1. U.S. Agency for International Development (2015) Multi-sectoral nutrition strategy technical brief: Nutrition, Food Security and HIV. USAID.

2. Joint United Nations Programme on HIVIAIDS (UNAIDS) (2014) Global statistics fact sheet report. UNAIDS.

3. Central Statistical Agency (CSA) (2011) Ethiopia demographic and health survey. Central Statistical Agency and ICF International USAID, Addis Ababa.

4. Louise Cl, Kimberly AC, Kenneth AF, Steven B, Jennifer C, et al. (2009) HIV/ AIDS, under nutrition and food insecurity. Clin Infect Dis 4: 1096-1102.

5. Palermo T, Rawat R, Weiser SD, Kadiyala S (2013) Food access and diet quality are associated with quality of life outcomes among HIV-Infected individuals in Uganda. PLoS ONE 8: 62353.

6. Food and Agriculture Organization of the United Nations (FAO) (2015 The International Fund for Agricultural Development (IFAD), World Food Programme (WFP). The State of Food Insecurity in the World. Meeting the 2015 international hunger targets: Taking stock of uneven progress. FAO, Rome.

7. Federal Minster of Health (2015) Health service delivery and quality of care HSDP-IV Annual Performance Report EFY.

8. World Food Programme (WFP), Joint United Nations Programme on HIVIAIDS (UNAIDS) (2014) Guidance note on food and nutrition resource kit for high impact programming. JC 2568: 1-7.

9. World Health Organization (WHO), World Food Programme (WFP), Joint United Nations Programme on HIVIAIDS (UNAIDS) (2014) UNAIDS Policy Brief: HIV, Food Security And Nutrition.

10. Swaminathan S, Padmapriyadarsini C, Yoojin L, Sukumar B, lliayas S, et al (2010) Nutritional Supplementation in HIV-Infected Individuals in South India: A Prospective Interventional Study. Clin Infect Dis 51: 51-57. 
Citation: Shiferaw WG, Jegora AA, Lema L, Gebremariam BM (2017) Under Nutrition Status and Its Determinants among Adult HIV and AIDS Clients Enrolled on Antiretroviral Therapy at Nigest Elleni Mohammed Memorial Hospital, Southern Ethiopia. J AIDS Clin Res 8: 733. doi: 10.4172/2155-6113.1000733

Page 6 of 6

11. Paton NI, Sangeetha S, Earnest A, Bellamy R (2006) The impact of malnutrition on survival and CD4 count response in HIV-infected patients starting antiretroviral therapy. HIV Med 7: 323-330.

12. Federal Democratic Republic of Ethiopia Ministry of Health (2006) National guidelines for HIVIAIDS and nutrition.

13. Federal HIVIAIDS Prevention and Control Office (2012) Ethiopia country progress report on HIVIAIDS Response. HAPCO, Addis Ababa, Ethiopia

14. Mette FO, Alemseged A, Pernille K, Markos T, Daniel Y, et al. (2014) Effects of nutritional supplementation for HIV patients starting antiretroviral treatment: Randomised controlled trial in Ethiopia. BMJ 348: 3187

15. Charles EO, Obinna IE (2014) Self-reported adherence to antiretroviral therapy in sub-Saharan Africa: A meta-analysis. Int J Public Health Epidemiol 3: $017-$ 025

16. Rajshree T, Archana A, Durga PP, Kiran B, Sophia NM (2015) Nutritional status and its association with quality of life among people living with HIV attending public anti-retroviral therapy sites of Kathmandu Valley, Nepal. AIDS Res Ther 12: 14

17. Molla D, Fekadu M, Dereje B (2013) Nutritional status and associated factors among adult HIVIAIDS clients in Felege Hiwot Referral Hospital, Bahir Dar, Ethiopia. Sci J Public Health 1: 24-31.

18. Meskerem Ak, Sileshi G, HabtamuFG (2015) Assessment of adult nutritional status and associated Factors among ART Users in Nekemte Referral Hospital and Health Center, East Wollega Zone, Ethiopia. Adv Life Sci Technol 29: 91 99.

19. Dereje G, Baye G, DagnachewM, Molla M (2015) Prevalence of malnutrition and its associated factors among adult people living with HIVIAIDS receiving anti-retroviral therapy at Butajira Hospital, southern Ethiopia. BMC Nutr 1: 5.

20. Negassie B, Desalegn T, Mekuriaw A (2013) Effect of nutritional factors on adherence to antiretroviral therapy among HIV-infected adults: A case control study in Northern Ethiopia. BMC Infect Dis 13: 233.

21. Louise Cl, Yuchiao C, Gregory J, Kenneth AF (2010) Food assistance is associated with improved body mass index, food security and attendance at clinic in an HIV program in central Haiti: A prospective observational cohor study. AIDS Res Ther 7: 33.

22. Rahul R, Suneetha K, Paul EM (2010) The impact of food assistance on weigh gain and disease progression among HIV-infected individuals accessing AIDS care and treatment services in Uganda. BMC Public Health 10: 316. 